Revista Destaques Acadêmicos, Lajeado, v. 12, n. 3, 2020. ISSN 2176-3070

DOI: http://dx.doi.org/10.22410/issn.2176-3070.v12i3a2020.2674

http://www.univates.br/revistas

\title{
ATIVIDADE FÍSICA NO AMBIENTE DE TRABALHO: UM ESTUDO DE REVISÃO
}

\author{
Luiz Cezar Lima Junior ${ }^{1}$, Nayane Nazareth Ferreira Lima ${ }^{2}$
}

Resumo: Objetivo: Avaliar a efetividade e fornecer evidências a respeito da prática de atividade física no ambiente de trabalho. Método: A revisão sistemática é uma aplicação de estratégias cientificas que permitem limitar o viés de seleção de artigos, avaliá-los com espírito crítico e sintetizar todos os estudos relevantes em um tópico específico. A pesquisa buscou artigos indexados no período de janeiro a março de 2017, nas bases de dados Scielo, PubMed e Google Acadêmico, com o intuito de identificar artigos relacionados com atividade física, qualidade de vida, ambiente de trabalho. Os critérios de inclusão do estudo foram: Artigos completos e gratuitos publicados nas línguas portuguesa e inglesa no período de 2007 a 2017 e que se reportavam sobre o tema proposto pelos autores (Atividade física, qualidade de vida e ambiente de trabalho). Resultados e discussão: Neste estudo foram encontrados 705 artigos na qual após a leitura dos resumos selecionamos 18 artigos. Posteriormente com os 18 artigos que constituíram a amostra do estudo, considerando já os critérios de exclusão os artigos contemplando autor, ano, foco, abordagem, resultados, fonte e palavras-chave. Entretanto, os estudos científicos que analisam a Qualidade de Vida e a Qualidade de Vida no Trabalho são recentes, sendo que estes temas foram mais abordados nas últimas décadas. Conclusão: Neste sentido, a pesquisa possibilitou identificar alguns aspectos que vêm marcando a temática estudada, e as evidências científicas acerca das intervenções em atividade física, qualidade de vida e saúde do trabalhador apontou para a importância de intervenções assertivas no ambiente de trabalho.

Palavras-chave: Qualidade de Vida. Trabalho. Saúde do trabalhador.

1 Mestre em Desenvolvimento e Meio Ambiente, pela Universidade Federal de Sergipe (UFS) Especialista em Bases Nutricionais da Atividade Física, bacharel em Educação Física pela Universidade Tiradentes (UNIT) e graduado em Licenciatura pela Claretiano. Professor da rede estadual de ensino.

2 Especialização em Clínica Médica pela (HGE) Alagoas, graduada em medicina pela Universidade Tiradentes (UNIT). 


\section{INTRODUÇÃO}

As mudanças no ambiente de trabalho e os processos produtivos acelerados nos últimos anos, junto com a informática e as mudanças no estilo de vida das pessoas contribuíram para o aumento do sedentarismo e consequentemente com a deterioração das condições de saúde dos trabalhadores, em especial dos indivíduos que desenvolvem atividades no escritório. Os indivíduos que trabalham são expostos a tensões que somadas as exigências normais de suas atividades, podem provocar o surgimento de doenças ou queixas relacionadas com o trabalho exaustivo.

As novas inovações tecnológicas e organizacionais deram uma nova feição na relação entre homem e o trabalho, onde exigi cada vez mais da capacidade de adaptação aos novos inventos, como máquinas, equipamentos e computadores. Por outro lado, ocorreu um aumento das doenças ocupacionais em decorrência dos esforços repetitivos, estresse e maior exigência no ambiente de trabalho (CANDOTTI, 2011; ISPAH, 2010). Para Rampanelli, (2010) o fator primordial para uma perspectiva de vida mais longa está relacionado com as condições em que o ser humano vive, sendo consequência de um conjugado de parâmetros singulares e socioambientais que podem ou não ser modificado.

Para Coutinho e Santos (2010) o acúmulo de tarefas, altas pressões na realização delas, condições de trabalho inadequadas e a falta de interesse na atividade profissional desempenhada são fatores determinantes para o estresse dentro do ambiente de trabalho. Podendo o indivíduo nessas situações aderir problemas de saúde física e emocional alterando até mesmo o seu comportamento no trabalho e na sua vida familiar.

A saúde do trabalhador está diretamente relacionada ao modo de vida e trabalho das populações, não havendo uma dissociação entre produção, trabalho, saúde e ambiente, pois assim como o trabalho promove subsistência, saúde e bem-estar, também desencadeia resultados negativos como o aumento da taxa de absenteísmo e afastamento em consequência das doenças ocupacionais (SANTANA, 2016).

Nesse sentido a qualidade de vida no trabalho é determinante para a empresa, onde poderá envolver uma implementação de melhorias e inovações no ambiente e trabalho, na qual a empresa tem que ter consciência de que o grande desafio de hoje do trabalhador é viver com qualidade num mundo hoje de alto desenvolvimento tecnológico, conciliando o trabalho da sua vida pessoal. Dentre as formas de contribuir para que os trabalhadores se encontrem em estado de saúde e não de doença.

Oliveira e Andrade (2013) apontam para a utilização da atividade física para promoção de saúde vem sendo disseminado há décadas pela comunidade cientifica, sendo comprovada a prática e a efetividade na redução de morbidade e mortalidade de indivíduos ativos. Para MACIEL et al., (2016) destacam para os benefícios na qualidade de vida do trabalhador proporcionado pela prática de 
atividade física, no que compete aos aspectos psicológicos, sociais e cognitivos e ainda, em consequência da adoção desde hábito saudável a percepção da sobrecarga laboral amenizada.

Segundo Silva et al., (2010) a prática regular de atividade física proporcionará benéficos na saúde das pessoas, podendo até mesmo diminuir ou melhorar os males que o estresse provoca no trabalho. Além disso, o exercício físico apresenta componentes biopsicossociais, culturais e de comportamento, podendo ser exemplificada por atividades laborais, jogos, brincadeiras entre outros.

A prática da atividade física pode contribuir para uma melhora das condições de saúde, além de uma maior disposição, menores chances de adquirir a obesidade, minimizar os sintomas da depressão e melhorar a qualidade de vida de quem pratica. Nesse sentido é possível dizer que ainda sobre a importância desses benefícios na classe trabalhadora, uma vez que as situações que vivenciam no ambiente de trabalho contribuem para que essas variáveis se agravem. Sendo assim, o mais importante seria que a classe trabalhadora, que é sujeita a diversas situações estressoras em seu ambiente de trabalho aproveitasse o tempo livre com atividades físicas para se beneficiar com a promoção da saúde, se socializar com outros trabalhadores, melhorar a qualidade de vida, dentre outros. Dessa forma o ambiente de trabalho pode apresentar também um local propicio para se desenvolver programas de intervenção a melhoria da saúde e atividade física, pois trata-se de um local que corresponde a maior parte do dia dos trabalhadores. (NAHAS et al., 2010). Assim a partir da avaliação de estudos de qualidade metodológica, o objetivo desta revisão foi avaliar a efetividade e fornecer evidências a respeito da prática de atividade física no ambiente de trabalho.

\section{METODOLOGIA}

A revisão sistemática é uma aplicação de estratégias cientificas que permitem limitar o viés de seleção de artigos, avaliá-los com espírito crítico e sintetizar todos os estudos relevantes em um tópico específico (PERISSÉ; GOMES; NOGUEIRA, 2001). Realizou-se a busca de artigos indexados no período de janeiro a março de 2017, nas bases de dados Scielo, PubMed e Google Acadêmico, com o intuito de identificar pesquisas relacionadas com atividade física, qualidade de vida, ambiente de trabalho. Os critérios de inclusão do estudo foram: Artigos completos e gratuitos publicados nas línguas portuguesa e inglesa no período de 2007 a 2017 e que se reportavam sobre o tema proposto pelos autores (Atividade física, qualidade de vida e ambiente de trabalho) para os critérios de exclusão foram os artigos que não apresentaram textos completos publicados na integra e que não repostavam nenhuma especificação do tema proposto. 
A partir desse levantamento bibliográfico para facilitar a seleção, categorização das informações e análise dos estudos, de modo a avaliar e discutir os aspectos principais apresentados nos estudos com relação a temática elaborou-se um roteiro composto pelos seguintes itens: autor, ano, foco, abordagem, resultados, fonte e palavras-chaves.

Seguindo a estratégia definida a pesquisa em base de dados resultou em 705 artigos, os artigos que não focavam em atividade física, qualidade de vida, ambiente de trabalho e doenças ocupacionais foram desconsiderados. Após adoção dos critérios sistemáticos citados foram incluídos 18 artigos, os quais se adequaram aos critérios do estudo proposto.

\section{RESULTADOS E DISCUSSÕES}

A atividade física no ambiente de trabalho apresenta-se como uma estratégia de melhorar a qualidade de vida do trabalhador e estudos que investiguem seus efeitos e sua viabilidade é necessária para construir uma base cientifica para que esta seja aplicada. Neste estudo foram encontrados 705 artigos na qual após a leitura dos resumos selecionamos 18 artigos. Posteriormente com os 18 artigos que constituíram a amostra do estudo, considerando já os critérios de exclusão os artigos contemplando autor, ano, foco, abordagem, resultados, fonte e palavras-chave.

Quadro 1: Descrição dos artigos sobre Atividade Física e cuidados com a Saúde no ambiente de trabalho, segundo autor, ano, foco, quantitativo da abordagem, resultados, fonte e palavras-chaves

\begin{tabular}{|c|c|c|c|c|c|c|}
\hline Autores & Ano & Foco & \begin{tabular}{|c|}
$\begin{array}{c}\text { Quantitativo } \\
\text { da aborda- } \\
\text { gem }\end{array}$ \\
\end{tabular} & Resultados & Fonte & $\begin{array}{l}\text { Palavras-Cha- } \\
\text { ves }\end{array}$ \\
\hline $\begin{array}{l}\text { Costa, } \\
\text { Brasil }\end{array}$ & 2012 & $\begin{array}{l}\text { Avaliar, comparativa- } \\
\text { mente, a qualidade de } \\
\text { vida e a capacidade de } \\
\text { trabalho de trabalhado- } \\
\text { res industriais. }\end{array}$ & Quantitativo & $\begin{array}{l}\text { Os Homens ob- } \\
\text { tiveram maiores } \\
\text { capacidades de } \\
\text { trabalho e ao pas- } \\
\text { so que mulheres } \\
\text { de } 30 \text { a } 39 \text { anos } \\
\text { a pres e n ta ra m } \\
\text { piores índices de } \\
\text { qualidade de vida }\end{array}$ & \begin{tabular}{|l|} 
Ciênc. Saú- \\
de coletiva \\
vol.17 no.6 \\
Rio de \\
Janeiro
\end{tabular} & $\begin{array}{l}\text { Categorias de } \\
\text { trabalhadores, } \\
\text { autoimagem, } \\
\text { organizaçã o } \\
\text { mundial da } \\
\text { saúde, carga de } \\
\text { trabalho, con- } \\
\text { duta de saúde }\end{array}$ \\
\hline $\begin{array}{l}\text { Rongen, } \\
\text { Holan- } \\
\text { da }\end{array}$ & 2012 & $\begin{array}{l}\text { Estudar eficácia dos } \\
\text { programas de promoção } \\
\text { da saúde no local de } \\
\text { trabalho. }\end{array}$ & $\begin{array}{l}\text { Revisão } \\
\text { sistemática }\end{array}$ & $\begin{array}{l}\text { Parcialmente } \\
\text { determinada por } \\
\text { características } \\
\text { de intervenção e } \\
\text { análise. }\end{array}$ & \begin{tabular}{|l|} 
American \\
Journal of \\
Preventive \\
Medicine
\end{tabular} & $\begin{array}{l}\text { Saúde, trabalho } \\
\text { e qualidade de } \\
\text { vida }\end{array}$ \\
\hline
\end{tabular}




\begin{tabular}{|c|c|c|c|c|c|c|}
\hline Autores & Ano & Foco & $\begin{array}{c}\text { Quantitativo } \\
\text { da aborda- } \\
\text { gem }\end{array}$ & Resultados & Fonte & $\begin{array}{l}\text { Palavras-Cha- } \\
\text { ves }\end{array}$ \\
\hline $\begin{array}{l}\text { Ruta- } \\
\text { nem, } \\
\text { Filandia }\end{array}$ & 2014 & $\begin{array}{l}\text { Avaliar os efeitos do } \\
\text { exercício físico sobre a } \\
\text { capacidade para o traba- } \\
\text { lho e esforço diário. }\end{array}$ & Quantitativo & $\begin{array}{l}\text { O aumento dos } \\
\text { recursos mentais } \\
\text { e a diminuição } \\
\text { do esforço físico } \\
\text { foram significati- } \\
\text { vamente maiores } \\
\text { entre o grupo de } \\
\text { intervenção do } \\
\text { que entre o grupo } \\
\text { controle }(\mathrm{p}<0,05) \\
\end{array}$ & $\begin{array}{l}\text { Pubmed. } \\
\text { com }\end{array}$ & $\begin{array}{l}\text { Capacidade de } \\
\text { trabalho, tensão } \\
\text { no trabalho, } \\
\text { exercício físico }\end{array}$ \\
\hline $\begin{array}{l}\text { Ferreira, } \\
\text { brasil }\end{array}$ & 2016 & $\begin{array}{l}\text { Identificar como um } \\
\text { programa de exercícios } \\
\text { físicos pode influenciar } \\
\text { a vida do trabalhado da } \\
\text { indústria, alterando seus } \\
\text { hábitos para aquisição } \\
\text { de um estilo de vida } \\
\text { mais saudável. }\end{array}$ & Quantitativo & \begin{tabular}{l|} 
Trabalhadores \\
relataram estarem \\
mais atentos à \\
saúde e qualidade \\
de vida
\end{tabular} & $\begin{array}{l}\text { Revista } \\
\text { Carioca de } \\
\text { Educação } \\
\text { Física, Vol. } \\
11\end{array}$ & $\begin{array}{l}\text { Qualidade de } \\
\text { vida; atividade } \\
\text { física, Fitness }\end{array}$ \\
\hline $\begin{array}{l}\text { Grande, } \\
\text { Brasil }\end{array}$ & 2013 & $\begin{array}{l}\text { Analisar fatores deter- } \\
\text { minantes na qualidade } \\
\text { de vida após três meses } \\
\text { de programa de promo- } \\
\text { ção a saúde do traba- } \\
\text { lhador }\end{array}$ & $\begin{array}{l}\text { Estudo Ex- } \\
\text { perimental }\end{array}$ & \begin{tabular}{l|} 
Comparando os \\
dados nacionais \\
com os do pre- \\
sente estudo para \\
todas as doenças \\
crônicas autor \\
referidas, foram \\
observadas dife- \\
renças estatísticas \\
significantes para \\
hipertensão, asma \\
e tireopatias (p < \\
0,0001). A prática \\
de atividade física \\
por motivos es- \\
téticos influencia \\
negativamente
\end{tabular} & $\begin{array}{l}\text { Rev. Bras. } \\
\text { Med. } \\
\text { Esporte } \\
\text { - Vol. 19, } \\
\text { N. } 5\end{array}$ & $\begin{array}{l}\text { Atividade mo- } \\
\text { tora, saúde do } \\
\text { trabalhador, } \\
\text { vigilância em } \\
\text { saúde do tra- } \\
\text { balhador, pro- } \\
\text { grama de saúde } \\
\text { ocupacional. }\end{array}$ \\
\hline $\begin{array}{l}\text { Santos, } \\
\text { Brasil }\end{array}$ & 2011 & $\begin{array}{l}\text { Avaliar o impacto de } \\
\text { um programa para pre- } \\
\text { venir a DORT (distúrbio } \\
\text { osteomuscular relacio- } \\
\text { nado ao trabalho), sobre } \\
\text { a qualidade de vida em } \\
\text { dois grupos. }\end{array}$ & Quantitativo & $\begin{array}{l}\text { O grupo de inter- } \\
\text { venção foi subme- } \\
\text { tido a orientações } \\
\text { especificas para } \\
\text { a prevenção de } \\
\text { DORT (distúrbio } \\
\text { osteomuscular re- } \\
\text { lacionado ao tra- } \\
\text { balho), enquanto } \\
\text { o grupo-controle } \\
\text { recebeu educação } \\
\text { sanitária. Não } \\
\text { houve diferenças } \\
\text { estatisticamente } \\
\text { significativas } \\
\text { entre os grupos } \\
\text { (p > 0,05). }\end{array}$ & $\begin{array}{l}\text { BMC pub- } \\
\text { lic health } \\
\text { (Online). } \\
\text { London. } \\
\text { Vol. } 11\end{array}$ & $\begin{array}{l}\text { Doenças profis- } \\
\text { sionais, Educa- } \\
\text { ção de pacien- } \\
\text { tes e Qualidade } \\
\text { de vida }\end{array}$ \\
\hline
\end{tabular}




\begin{tabular}{|c|c|c|c|c|c|c|}
\hline Autores & Ano & Foco & $\begin{array}{c}\text { Quantitativo } \\
\text { da aborda- } \\
\text { gem }\end{array}$ & Resultados & Fonte & $\begin{array}{l}\text { Palavras-Cha- } \\
\text { ves }\end{array}$ \\
\hline $\begin{array}{l}\text { Oli- } \\
\text { veira, } \\
\text { Brasil }\end{array}$ & 2012 & $\begin{array}{l}\text { Analisar as condições de } \\
\text { trabalho de professoras } \\
\text { do ensino superior da } \\
\text { área da saúde e suas im- } \\
\text { plicações sobre a saúde e } \\
\text { qualidade de vida. }\end{array}$ & Qualitativo & $\begin{array}{l}\text { Ausência de lazer } \\
\text { com consequen- } \\
\text { tes distúrbios } \\
\text { do sono, favore- } \\
\text { cendo doenças } \\
\text { psíquicas; excesso } \\
\text { de trabalho; alte- } \\
\text { rações significa- } \\
\text { tivas na forma de } \\
\text { organização do } \\
\text { mesmo, influen- } \\
\text { ciando negativa- } \\
\text { mente a saúde e } \\
\text { a qualidade de } \\
\text { vida. }\end{array}$ & $\begin{array}{l}\text { Ciênc. saú- } \\
\text { de coletiva } \\
\text { vol.17 no.3 }\end{array}$ & $\begin{array}{l}\text { Gênero, Quali- } \\
\text { dade de vida, } \\
\text { docentes }\end{array}$ \\
\hline $\begin{array}{l}\text { Ferra- } \\
\text { cini, } \\
\text { Brasil }\end{array}$ & 2010 & $\begin{array}{l}\text { Avaliar a presença de } \\
\text { sintomas musculoes- } \\
\text { queléticos e os efeitos de } \\
\text { um programa de grupo } \\
\text { laboral (GL) em funcio- } \\
\text { nários do setor adminis- } \\
\text { trativo }\end{array}$ & $\begin{array}{l}\text { Estudo Ex- } \\
\text { perimental }\end{array}$ & $\begin{array}{l}\text { Houve resultados } \\
\text { significativos na } \\
\text { redução da dor } \\
\text { musculoesque- } \\
\text { lética, durante e } \\
\text { após a jornada de } \\
\text { trabalho, }\end{array}$ & $\begin{array}{l}\text { Revista } \\
\text { Dor, v. } 11\end{array}$ & $\begin{array}{l}\text { Distúrbios os- } \\
\text { teomusculares } \\
\text { relacionados ao } \\
\text { trabalho, Gi- } \\
\text { nástica laboral, } \\
\text { Saúde do traba- } \\
\text { lhador. } \\
\end{array}$ \\
\hline \begin{tabular}{l|} 
Freitas \\
Robazzi, \\
Brasil
\end{tabular} & 2014 & $\begin{array}{l}\text { Avaliar o efeito de um } \\
\text { programa de Ginástica } \\
\text { Laboral compensatória } \\
\text { em trabalhadores, visan- } \\
\text { do a redução do estresse } \\
\text { ocupacional e da dor } \\
\text { osteomuscular. }\end{array}$ & Quantitativo & $\begin{array}{l}\text { A Ginastica la- } \\
\text { boral promove } \\
\text { redução significa- } \\
\text { tiva de algias na } \\
\text { coluna vertebral; } \\
\text { todavia, não pro- } \\
\text { moveu redução } \\
\text { significativa dos } \\
\text { níveis de estresse } \\
\text { ocupacional }\end{array}$ & $\begin{array}{l}\text { Revista La- } \\
\text { tino-Ame- } \\
\text { ricana de } \\
\text { Enferma- } \\
\text { gem (USP } \\
\text { Ribeirão } \\
\text { Preto. } \\
\text { Impresso), } \\
\text { v. 22, }\end{array}$ & $\begin{array}{l}\text { Estresse Ocu- } \\
\text { pacional; Dor } \\
\text { Musculoesque- } \\
\text { lética; Saúde do } \\
\text { Trabalhador; } \\
\text { trabalhador }\end{array}$ \\
\hline $\begin{array}{l}\text { Candot- } \\
\text { ti, Brasil }\end{array}$ & 2011 & $\begin{array}{l}\text { Verificar se um progra- } \\
\text { ma de Ginastica Laboral } \\
\text { motiva seus participan- } \\
\text { tes a realizar atividade } \\
\text { física regular fora do } \\
\text { ambiente laboral }\end{array}$ & $\begin{array}{l}\text { Estudo ex- } \\
\text { ploratório }\end{array}$ & $\begin{array}{l}\text { Indicaram que } \\
92,7 \%(\mathrm{n}=51) \\
\text { dos trabalhadores } \\
\text { sedentários sen- } \\
\text { tem-se motivados } \\
\text { a praticar alguma } \\
\text { atividade física. } \\
\text { Conclui-se que a } \\
\text { GL pode ser uti- } \\
\text { lizada como uma } \\
\text { ferramenta eficaz } \\
\text { para motivar } \\
\text { seus participan- } \\
\text { tes a realizarem } \\
\text { atividade física } \\
\text { regular. }\end{array}$ & $\begin{array}{l}\text { Revista } \\
\text { Baiana } \\
\text { de Saúde } \\
\text { Pública, } \\
\text { v. } 35\end{array}$ & $\begin{array}{l}\text { Exercício Saúde } \\
\text { do Trabalha- } \\
\text { dor, Qualidade } \\
\text { de Vida }\end{array}$ \\
\hline $\begin{array}{l}\text { Couto } \\
\text { Pas- } \\
\text { choal, } \\
\text { Brasil }\end{array}$ & 2012 & $\begin{array}{l}\text { Investigar o impacto de } \\
\text { atividades organizacio- } \\
\text { nais voltadas à saúde } \\
\text { do trabalhador sobre o } \\
\text { bem-estar no trabalho }\end{array}$ & Quantitativo & $\begin{array}{l}\text { Quanto mais os } \\
\text { trabalhadores } \\
\text { participavam } \\
\text { de atividades } \\
\text { voltadas a saúde, } \\
\text { menos frequentes } \\
\text { e intensas eram } \\
\text { suas experiências } \\
\text { afetivas negativas }\end{array}$ & $\begin{array}{l}\text { Revista } \\
\text { Psicologia } \\
\text { Argumen- } \\
\text { to, v. } 30\end{array}$ & $\begin{array}{l}\text { Qualidade de } \\
\text { vida, trabalho } \\
\text { e realização } \\
\text { pessoal }\end{array}$ \\
\hline
\end{tabular}




\begin{tabular}{|c|c|c|c|c|c|c|}
\hline Autores & Ano & Foco & \begin{tabular}{|c|}
$\begin{array}{c}\text { Quantitativo } \\
\text { da aborda- } \\
\text { gem }\end{array}$ \\
\end{tabular} & Resultados & Fonte & $\begin{array}{l}\text { Palavras-Cha- } \\
\text { ves }\end{array}$ \\
\hline $\begin{array}{l}\text { Gazma- } \\
\text { rarian, } \\
\text { Atlanta }\end{array}$ & 2013 & $\begin{array}{l}\text { Avaliar a eficácia de } \\
\text { abordar múltiplas } \\
\text { barreiras à atividade } \\
\text { física (PA) usando in- } \\
\text { tervenções no local de } \\
\text { trabalho. }\end{array}$ & $\begin{array}{l}\text { O Estudo } \\
\text { de ativida- } \\
\text { de física e } \\
\text { estilo de } \\
\text { vida usou } \\
\text { um estudo } \\
\text { controlado } \\
\text { randomiza- } \\
\text { do em que } \\
60 \text { departa- } \\
\text { mentos uni- } \\
\text { versitários } \\
\text { foram ran- } \\
\text { domizados } \\
\text { em cinco } \\
\text { grupos } \\
\end{array}$ & $\begin{array}{l}\text { Entre os adultos } \\
\text { sedentários que } \\
\text { tiveram acesso a } \\
\text { instalações para } \\
\text { exercícios inter- } \\
\text { nos, abordar as } \\
\text { barreiras ambien- } \\
\text { tais e cognitivas } \\
\text { simultaneamente } \\
\text { (ou seja, tempo } \\
\text { e educação) não } \\
\text { encorajaram mais } \\
\text { atividade do que } \\
\text { abordar qualquer } \\
\text { barreira isolada- } \\
\text { mente. } \\
\end{array}$ & \begin{tabular}{|l|} 
American \\
Journal \\
of Health \\
Promotion, \\
forthcom- \\
ing.
\end{tabular} & $\begin{array}{l}\text { Atividade físi- } \\
\text { ca, bem-estar } \\
\text { no local de tra- } \\
\text { balho e pesqui- } \\
\text { sa de prevenção }\end{array}$ \\
\hline $\begin{array}{l}\text { Grande, } \\
\text { Brasil }\end{array}$ & 2013 & $\begin{array}{l}\text { Comparar diferentes } \\
\text { intervenções de promo- } \\
\text { ção à saúde do trabalha- } \\
\text { dor e seu impacto nos } \\
\text { domínios da qualidade } \\
\text { de vida }\end{array}$ & $\begin{array}{l}\text { Ensaio clíni- } \\
\text { co controla- } \\
\text { do randomi- } \\
\text { zado }\end{array}$ & \begin{tabular}{|l|} 
As empresas que \\
receberam a ativi- \\
dade física pro- \\
moveram bene- \\
fício no domínio \\
do ambiente de \\
trabalho. \\
\end{tabular} & \begin{tabular}{|l|} 
Revista \\
Brasileira \\
de Cinean- \\
tropome- \\
tria \& De- \\
sempenho \\
Humano \\
\end{tabular} & $\begin{array}{l}\text { Atividade } \\
\text { física; Promo- } \\
\text { ção da saúde; } \\
\text { Qualidade de } \\
\text { vida; Saúde do } \\
\text { trabalhador. }\end{array}$ \\
\hline $\begin{array}{l}\text { Aguiar, } \\
\text { Brasil }\end{array}$ & 2017 & $\begin{array}{l}\text { Avaliar a influência } \\
\text { de um programa de } \\
\text { promoção de saúde na } \\
\text { qualidade de vida de } \\
\text { funcionárias do setor } \\
\text { administrativo de uma } \\
\text { instituição de ensino } \\
\text { superior }\end{array}$ & Quantitativo & $\begin{array}{l}\text { Confirmar a as- } \\
\text { sociação positiva } \\
\text { entre a participa- } \\
\text { ção em um pro- } \\
\text { grama de saúde } \\
\text { do trabalhador e } \\
\text { melhor qualidade } \\
\text { de vida, o que } \\
\text { reforça a necessi- } \\
\text { dade de um estilo } \\
\text { de vida ativa ao } \\
\text { longo do processo } \\
\text { de vida laboral } \\
\text { dos trabalhadores }\end{array}$ & $\begin{array}{l}\text { Revista } \\
\text { fisiotera- } \\
\text { pia e rea- } \\
\text { bilitação, } \\
\text { v.1, n } 2\end{array}$ & $\begin{array}{l}\text { Atividade físi- } \\
\text { ca. Qualidade } \\
\text { de vida. Traba- } \\
\text { lhador. }\end{array}$ \\
\hline $\begin{array}{l}\text { Johns- } \\
\text { ton, } \\
\text { Austrá- } \\
\text { lia }\end{array}$ & 2014 & $\begin{array}{l}\text { Investigar se a intro- } \\
\text { dução de ergonomia e } \\
\text { exercícios no local de } \\
\text { trabalho poderia mini- } \\
\text { mizar a dor cervical }\end{array}$ & Quantitativo & \begin{tabular}{|l|} 
Protocolo. Re- \\
sultados serão \\
divulgados após \\
12 meses de inter- \\
venção. \\
\end{tabular} & $\begin{array}{l}\text { Journal of } \\
\text { Physiothe- } \\
\text { rapy }\end{array}$ & $\begin{array}{l}\text { Exercício no } \\
\text { local de traba- } \\
\text { lho, promoção } \\
\text { da saúde, dor } \\
\text { cervical } \\
\end{array}$ \\
\hline $\begin{array}{l}\text { Serra, } \\
\text { Brasil }\end{array}$ & 2014 & $\begin{array}{l}\text { Análise crítica acerca da } \\
\text { contribuição da GinL na } \\
\text { saúde do trabalhador. }\end{array}$ & $\begin{array}{l}\text { Revisão in- } \\
\text { tegrativa da } \\
\text { bibliografia }\end{array}$ & \begin{tabular}{|l|} 
Mostraram que a \\
GL pode ser uma \\
forma potencial \\
de intervenção \\
para minimizar \\
os problemas de \\
saúde no local de \\
trabalho. \\
\end{tabular} & \begin{tabular}{|l|} 
Revista \\
Pesquisa \\
em Fisiote- \\
rapia
\end{tabular} & $\begin{array}{l}\text { Transtornos } \\
\text { traumáticos } \\
\text { cumulativos; } \\
\text { Doenças profis- } \\
\text { sionais; Saúde } \\
\text { do trabalhador; } \\
\text { Riscos ocupa- } \\
\text { cionais. } \\
\end{array}$ \\
\hline $\begin{array}{l}\text { Souza, } \\
\text { Brasil }\end{array}$ & 2015 & $\begin{array}{l}\text { Identificar como está a } \\
\text { saúde e qualidade de } \\
\text { vida dos funcionários } \\
\text { de uma gráfica e as } \\
\text { melhorias sentidas após } \\
\text { a implantação da Ginás- } \\
\text { tica Laboral. }\end{array}$ & $\begin{array}{l}\text { Pesquisa de } \\
\text { campo }\end{array}$ & $\begin{array}{l}\text { A importância } \\
\text { à continuidade } \\
\text { da pratica da } \\
\text { Ginastica Labo- } \\
\text { ral no ambiente } \\
\text { de trabalho } \\
\text { buscando adap- } \\
\text { tações e melhor } \\
\text { atendimento as } \\
\text { necessidades dos } \\
\text { funcionários. }\end{array}$ & $\begin{array}{l}\text { Saúde em } \\
\text { Foco, Edi- } \\
\text { ção } \mathrm{n}^{\circ}: 07\end{array}$ & $\begin{array}{l}\text { Saúde, trabalho } \\
\text { e qualidade de } \\
\text { vida }\end{array}$ \\
\hline
\end{tabular}




\begin{tabular}{|l|c|l|c|l|l|l|}
\hline Autores & Ano & Foco & $\begin{array}{l}\text { Quantitativo } \\
\text { da aborda- } \\
\text { gem }\end{array}$ & Resultados & Fonte & $\begin{array}{l}\text { Palavras-Cha- } \\
\text { ves }\end{array}$ \\
\hline $\begin{array}{l}\text { Biallas, } \\
\text { Alema- } \\
\text { nha }\end{array}$ & 2015 & $\begin{array}{l}\text { Analisar o efeito de } \\
\text { promoção da saúde no } \\
\text { local de trabalho sobre } \\
\text { capacidade para o traba- } \\
\text { lho e saúde relacionados } \\
\text { com qualidade de vida } \\
\text { no trabalho. }\end{array}$ & Quantitativo & $\begin{array}{l}\text { Promoção do } \\
\text { exercício no } \\
\text { contexto da pro- } \\
\text { moção da saúde } \\
\text { ocupacional teve } \\
\text { efeito positivo na } \\
\text { qualidade de vida } \\
\text { e capacidade para } \\
\text { o trabalho dos } \\
\text { funcionários. }\end{array}$ & $\begin{array}{l}\text { Thieme E - } \\
\text { Journals }\end{array}$ & $\begin{array}{l}\text { Promoção da } \\
\text { saúde no local } \\
\text { de trabalho - } \\
\text { capacidade de } \\
\text { trabalho - qua- } \\
\text { lidade de vida } \\
\text { relacionada à } \\
\text { saúde - ativida- } \\
\text { de física }\end{array}$ \\
\hline
\end{tabular}

Com relação a metodologia os estudos encontrados foram de predominância a abordagem quantitativa foram achados (9 artigos), na qual os estudos apresentam resultados positivos, onde a maioria dos estudos relatou melhoras na participação em programas de saúde do trabalhador e na qualidade de vida. $\mathrm{O}$ uso da atividade física a fim e promover saúde e consequente melhoria da qualidade de vida do trabalho foi verificado por meio de pesquisa realizada na Finlândia com mulheres na menopausa, observando aumento dos recursos mentais e diminuição do esforço físico (Rutanem, 2014). De modo geral, a maioria dos trabalhadores possui uma carga diária laboral de oito horas, ou seja, um terço das horas de um dia, sendo outro um terço gasto dormindo e o um terço restante gasto com locomoção e atividades diárias, como refeições, lazer e obrigações do dia a dia. Fatores como escassez do tempo e a alta carga horária diária de trabalho podem contribuir para o sedentarismo. Desse modo, a prática de atividade física no local de trabalho tem a capacidade de desenvolver melhores hábitos de vida e indicadores de saúde, podendo ajudar na saúde pública do país (GRANDE; SILVA; PARRA; 2014). No Brasil, um estudo buscou investigar fatores determinantes na qualidade de vida, após três meses de programa de promoção da saúde do trabalhador por meio de atividade física e orientações, onde constatou que os fatores que interferiram na qualidade de vida foram: prática de atividade física com objetivo estético, condição física, tabagismo, atividade física por recomendação médica, tempo sentada, vida em família, qualidade do sono e renda (GRANDE, 2013).

Na Alemanha, verificou-se o efeito da promoção da saúde por meio de atividade física no local de trabalho sobre capacidade para o trabalho e saúde relacionada com qualidade de vida de trabalhadores de uma empresa de médio porte. Evidenciou-se que a promoção do exercício no contexto da promoção da saúde ocupacional teve efeito positivo na qualidade de vida e capacidade para o trabalho dos funcionários e, portanto, é um benefício tanto para o indivíduo quanto para a empresa (Biallas, 2015). Pesquisa realizada no interior de São Paulo buscou comparar qualidade de vida e a capacidade de trabalho de trabalhadores industriais, observando que os homens jovens obtiveram valores maiores para capacidade de trabalho, enquanto as mulheres com idade entre 30 e 39 anos apresentaram os piores índices de qualidade de vida (Costa, 2012). 
Nos achados de revisão sistemática foram encontrados ( 1 artigo) mostrando a eficácia de programas de promoção da saúde no local de trabalho. Frente a esses estudos, elucida-se que programas de promoção da saúde no local de trabalho visam melhorar estilo de vida e, consequentemente, a saúde, capacidade para o trabalho e produtividade no trabalho (RONGEN, 2012). No estudo experimental foram encontrados (2 artigos) onde um estudo mostra resultados positivos na redução de dor muscular nos trabalhadores após a realização de sessões de atividade física. Além disso, foram observados também que a prática da atividade física estimulava aos trabalhadores a serem mais ativos fisicamente, havendo uma melhora no relacionamento interno nas empresas, redução das dores articulares na coluna, flexibilidade do tronco e do quadril, redução das dores musculoesqueléticas, disposição para trabalhar, melhoria da postura, melhor índice de massa corporal, aumento da força muscular, resistência dos músculos abdominais e costais e melhora na função cardiopulmonar ( Ferracini, 2010). Um estudo exploratório por (Candotti, 2011) identificou que $92,7 \%$ dos trabalhadores sedentários se sentem motivados a praticar alguma atividade física e vem a Ginastica Laboral uma oportunidade eficaz de motivação. Os benefícios da Ginastica Laboral não são ainda bem elucidados na literatura e a qualidade metodológica dos estudos ainda é baixa, entretanto, a importância do exercício físico já é bem documentada e tem impacto positivo na aptidão física relacionada à saúde e no perfil metabólico (ALENCAR; MATIAS, 2010). De acordo com Freitas e Robazzi (2014), a Ginastica Laboral tem apresentado benefícios quando executada em conjunto com outras ações de promoção à saúde dos trabalhadores. Em um achado de pesquisa de campo teve como o objetivo de identificar a saúde e a qualidade de vida dos funcionários de uma empresa e as melhoras sentidas após a implementação da atividade física, tendo como resultado importância da pratica da atividade física (Ginastica laboral) no ambiente de trabalho buscando adaptações e melhor atendimento as necessidades dos funcionários. ( 2 artigos) tratam de estudo de controle onde um achado avaliou a eficácia de abordar múltiplas barreiras à atividade física usando intervenções no local de trabalho e um outro estudo foi conduzido comparando diferentes intervenções de promoção à saúde do trabalhador e seu impacto nos domínios da qualidade de vida.

\section{CONCLUSÃO}

A pesquisa possibilitou identificar alguns aspectos que vêm marcando a temática estudada, e as evidências científicas acerca das intervenções em atividade física, qualidade de vida e saúde do trabalhador apontaram para a importância de intervenções assertivas no ambiente de trabalho.

Em relação às intervenções no local de trabalho relativas ao incentivo as atividades físicas e cuidados com a saúde, constatou-se que atividade física, melhora a postura corporal e que a ginástica laboral é um tipo de programa que vem sendo aplicado dentro das empresas visando a melhorar a saúde, 
autoestima, produtividade, proporcionando benefícios para a saúde do trabalhador, o outro ponto a ser observado são as demandas mentais decorrentes do trabalho, como por exemplo a baixa qualidade do sono, ambiente laboral inadequado, podendo ser amenizado por meio de intervenções especificas que proporcionarão melhora da saúde e bem-estar.

Constatou-se também que intervenções voltadas para a promoção da capacidade do trabalho e prevenção de doenças têm efeitos benéficos para os trabalhadores desde que sejam planejadas, implementadas e avaliadas.

\section{REFERÊNCIAS}

AGUIAR, D. C; LEITE, R. N; BELMONTE, L. M; BELMONTE, L. A. O; LIMA, I. A. $X$. A influência de um programa de promoção de saúde na qualidade de vida de funcionárias do setor administrativo de uma instituição de ensino superior. Rev. fisioter. reab. Palhoça, v. 1, n. 2, p. 10-18, 2017.

ALENCAR, T. A. M.; MATIAS, K. F. S. Princípios Fisiológicos do Aquecimento e Alongamento Muscular na Atividade Esportiva. Revista Brasileira de Medicina do Esporte (Impresso), v. 16, p. 230-234, 2010.

BIALLAS, B. Analysis of Workplace Health Promotion and its Efect on Work Ability and health-related quality of life in a medium-sized business. Europe PMC, 2015.

CANDOTTI, C. T; STROCHEIN, R. Efeitos da ginástica laboral na dor nas costas e nos hábitos posturais adotados no ambiente de trabalho. Rev. bras. Ciênc. Esporte. 2011.

COSTA, C. S. N; FREITAS, E. G; MENDONÇA, L. C. S; ALEM, M. E. R; COURY, H. J. C. G. Works ability and quality of life of Brazilian industrial workers. Ciênc. Saúde Colet. 2012.

COUTINHO, D. A.; SANTOS, J.W. O Estresse no mundo do trabalho: Uma abordagem individual e organizacional. Revista Científica Eletrônica de Psicologia, Garça/SP, ano VIII, n.14, 2013.

FERRACINI, G N; VALENTE, F. M. Presença de sintomas musculoesqueléticos e efeitos da ginástica laboral em funcionários do setor administrativo de um hospital público. Revista Dor, v. 11, p. 116-119, 2010.

FERREIRA, R. Um estudo de caso de um programa de qualidade de vida na empresa realizado pelo SESI-RJ, Revista Carioca de Educação Física, Vol. 11, Edição Especial, p. 42-50, 2016.

FREITAS, F. C. T; Robazzi, M. L. C. C. The effects of compensatory workplace exercises to reduce work-related stress and musculoskeletal pain. Revista LatinoAmericana de Enfermagem (USP Ribeirão Preto. Impresso), v. 22, p. 629-636, 2014. 
GAZMARARIAN J.A, et al. A randomized prospective trial of a worksite intervention program to increase physical activity. American Journal of Health Promotion, forthcoming. v.. 28, n. 1, p. 32-40,2013

GRANDE, A. J; SILVA, V; PARRA, S.A. Efetividade da ginástica laboral na aptidão física: estudo randomizado não-controlado. Einstein (São Paulo), v. 12, p. 55-60, 2014.

International Society for Physical Activity and Health (ISPAH). The Toronto charter for physical activity: a global call to action. Toronto: Global Advocacy Council for Physical Activity, International Society for Physical Activity and Health; 2010.

JOHNSTON, V. eat. A workplace exercise versus health promotion intervention to prevent and reduce the economic and personal burden of non-specific neck pain in office personnel: protocol of a cluster-randomised controlled trial. J Physiother. 2014

MACIEL, A. C. C; FERNANDES, M. B; MEDEIROS, L. S. Prevalência e fatores associados à sintomatologia dolorosa entre profissionais da indústria têxtil. Rev. Bras. Epidemia. 2006;9(1):94-102.

MACIEL, E, S. GOMES, G, A, O; SONATI, J, G; MODENEZE, D, M; QUARESMA, F, $R, P$; VILARAT, R. Influência do nível de atividade física na percepção da qualidade de vida em comunidade universitária. Rev. Bras. Qual. Vida. 2016.

NAHAS, M. V. et al. Lazer ativo: Um programa de promoção de estilos de vida ativos e saudáveis para o trabalhador da indústria. Revista Brasileira de Atividade Física \& Saúde, v. 15, n. 4, p. 260-264, 2010.

OLIVEIRA, E. R. A; GARCIA, A. L; GOMES, M. J; BITTAR, T. O; PREREIRA, A. C. Gender and perceived quality of life: research with professors from the health are. Ciênc. Saúde Colet. 2012.

PERISSÉ, A. R. S; GOME, M. M; NOGUEIRA, S. A. Revisões sistemáticas (inclusive metanálises) e diretrizes clínicas. In: Gomes MM, organizador. Medicina baseada em evidências: princípios e práticas. Rio de Janeiro (RJ): Reichmann \& Affonso; 2001.

RAMPANELLI, A. A prática de atividade Física entre mulheres Frequentadoras de academia no climatério e menopausa [dissertação]. Novo Hamburgo: Universidade Envale; 2010.

RESENDE, M. C. F; TEDESCHI; C. M; BETHÔNICO, F. P; MARTINS, T. T. M. Efeitos da ginástica laboral em funcionários de tele atendimento. 2007.

RONGEN, A. ROBROEK, S. J. VAN, LENTHE, F. J. BURDORF, A. Workplace health promotion: a meta-analysis of effectiveness. Am.J. Prev. Med. 2012.

RUTANEM, R; NYGARD, C. H; MOILANEM, J; MIKKOLA, T; RAITANEM, J; TOMAS, E. et al. Effect of physical exercise on work ability and daily strain in symptomatic menopausal women: a randomized controlled trial. 2014 
SANTANA, L, L; SARQUIS, L, M, M; MIRANADA, F, M, D; KALINKE, L, P; FELLI, $\mathrm{V}, \mathrm{E}, \mathrm{A} ; \mathrm{MIMINEL}, \mathrm{V}, \mathrm{A}$. Indicadores de saúde dos trabalhadores da área hospitalar. Rev Bras Enferm. 2016.

SANTOS, A. C; BREDEMEIER, M; ROSA, F. K; AMANTEA, V. A; XAVIER, R. M.

The impact of a program to prevent DORT (work-related musculoskeletal disorder), on quality of life in two groups. BMC public health (Online). London. Vol. 11. 2011.

SERRA, M. V. G. B; PIMENTA, L. C; QUEMELO, P. R. V. Efeitos da Ginastica Laboral na saúde do trabalhador: Uma revisão sistemática, revista pesquisa em Fisioterapia: 197-205. 2014.

SILVA, R. S. et al. Atividade física e qualidade de vida. Ciência \& Saúde Coletiva, v. 15, n. 1, p; 115-120, 2010.

SOUZA, A. P; eat. Qualidade de vida no trabalho utilizando a ginastica laboral. Saúde em Foco, Edição n ${ }^{\circ}:$ 07, 2015. 